Marquette University

e-Publications@Marquette

Psychology Faculty Research and Publications

Psychology, Department of

2-1-1977

\title{
Recall of Group Tasks as a Function of Group Cohesiveness and Interruption of Tasks
}

Anees A. Sheikh

Marquette University, anees.sheikh@marquette.edu

Richard J. Koch

Marquette University

Accepted version. Psychological Reports, Vol. 40, No. 1 (February 1, 1977): 275-278. DOI. (C 1977

SAGE Publication. Used with permission. 


\title{
Marquette University
}

\section{e-Publications@Marquette}

\section{Psychology Faculty Research and Publications/College of Arts and Sciences}

This paper is NOT THE PUBLISHED VERSION; but the author's final, peer-reviewed manuscript. The published version may be accessed by following the link in the citation below.

Psychological Reports, Vol. 40, No. 1 (February 1, 1977): 275-278. DOI. This article is (C) SAGE Publications and permission has been granted for this version to appear in e-Publications@Marquette. SAGE Publications does not grant permission for this article to be further copied/distributed or hosted elsewhere without the express permission from SAGE Publications.

\section{Recall of Group Tasks as a Function of Group Cohesiveness and Interruption of Tasks}

\author{
Anees A. Sheikh \\ Psychology, Marquette University, Milwaukee, WI \\ Richard J. Koch \\ Psychology, Marquette University, Milwaukee, WI
}

\section{Summary}

The paper demonstrates that the motivational concepts underlying the Zeigarnik effect pertaining to individuals attempting to achieve their personal goals can be applied to individuals who are working to attain the group goals. However, this is true only for individuals in cohesive groups as opposed to noncohesive groups.

Zeigarnik (1927) discovered that, if a subject was motivated to perform a series of tasks and was allowed to complete only a few of them, his memory of the incompleted tasks was better than his memory of the completed ones. Drawing upon Lewin's (1951) theory of motivation, Zeigarnik had assumed that the intention to reach a goal led to a psychological tension within the individual which remained active until the goal was reached; lack of completion of a task left the related tension system intact. Consequently, the tasks whose tension system was intact were recalled more often than tasks 
which had their tension system reduced by completion. These results are known as the Zeigarnik effect.

Horwitz (1954) extended the use of the Zeigarnik effect to investigate the individual's striving for group goals. He employed five-person groups that were led to compete in a series of group tasks. Half-way through each task, the experimenter asked the subjects to decide by secret ballot whether or not the group should complete the cask. In one-third of the cases, the experimenter announced that the majority opinion was against completing them ("N" tasks); concerning the remaining two-thirds of the tasks, the experimenter told the subjects that the vote was in favor of completing them ("Y" tasks). Half of the "Y" tasks were interrupted subsequent to the vote ("Y-I" tasks), and the remainder were completed by the group ("Y-C" tasks).

The results showed that the "Y-I" tasks were recalled more often than the "Y-C" or the "N tasks. The difference between the recall of " $\mathrm{Y}-\mathrm{C}$ " and " $\mathrm{N}$ " tasks was not significant. Additional analysis indicated that subjects who initially voted against continuing accepted the decision of the group after the vote and became motivated toward completing the tasks. Horwitz, in accordance with Lewin's theory, explained that when the group decision was to complete a task, a tension was induced in the individuals for achieving the group goal and this tension remained active until the task was completed. On the other hand, when the group voted against completing the task, no such tension was present.

In addition to replicating these important findings, the major goal of the present investigation was to discover the effects of group cohesiveness on the recall of group tasks. A cohesive group should be able to secure from its members a relatively high degree of acceptance of any group goal which is set for the group by the majority of the group (Krech, Crutchfield, \& Ballachey, 1962). Consequently, the interruption of group tasks should leave greater tension in the members of a cohesive group than in a noncohesive group, and the recall of these tasks should be affected accordingly. The variable of cohesiveness was manipulated experimentally.

\section{METHOD}

Ninety university students were randomly divided into 18 groups of five members each. Nine of the groups were randomly assigned to the high cohesive condition and the other nine to the lowcohesive condition.

An Attitude Survey Questionnaire was administered to all subjects at a prior date. When a group arrived for the experiment, the subjects were told that in the first part of the experiment they would be monitored by a polygraph while they viewed certain slides projected on the screen, and in the second part they would work to put together some simple five-piece jig-saw puzzles.

In the condition with high cohesiveness, experimenter informed the group that the Attitude Survey Questionnaire which chey had completed previously not only measured their attitudes, but also their ability to communicate with other individuals in a group. The experimenter then announced that the questionnaire showed that their particular group consisted of individuals with very similar attitudes. He further explained that the high similarity in attitude meant that the subjects would have a high level of "implicit communication skill" which would, probably, give them a big advantage over other groups in putting together puzzles in the second part of the experiment. The "implicit communication skill" was defined as a person's ability to communicate with other people, similar to himself, without the use of normal verbal or visual cues. The experimenter also explained that since the group had very similar attitudes, he would not be surprised if they would also have very similar 
physiological responses to slides which dealt with issues parallel to those examined in the questionnaire.

Subjects in the condition with low cohesiveness were given the same basic instructions but were told that their responses on the Attitude Survey Questionnaire had not been similar and that consequently they probably would not perform better than average in Part II of the experiment. They were told that their physiological responses would also probably be quite different.

Sixteen 35-mm, picture slides dealing with issues such as street crime, civil rights, sex, and war crimes were shown. Five meters were displayed in front of the subjects who were informed that the meters were connected to the poly graph and would show the relative change in the subjects' electrical stress resistance. The subjects were told that they would not be able to identify their own response because the relative order of the meters was scrambled.

A frequency generator was used to program various frequencies and amplitudes of sound with various time intervals onto the magnetic tape of a tape recorder. Five tapes, one for each highcohesiveness subject, were programmed to show a high degree of similar responses for all subjects in that group. Similarly, a set of tapes was prepared to show dissimilar responses for the subjects low in cohesiveness.

The procedure in this part of the experiment was identical to the one used by Horwitz (1954) except that the subjects were given a Post-experimental Questionnaire to determine whether or not high and low cohesiveness had indeed been created. For each question the subject had to choose between four answers which presumably indicated different degrees of cohesiveness.

\section{RESULTS}

The number of tasks recalled by the subjects were subjected to a $2 \times 3$ analysis of variance with repeated measures on one variable. The between-subjects factor referred to cohesiveness and the within-subjects factor pertained to the recall treatment condition ("Y-C" vs "N" vs "Y-I"). A significant main effect was obtained on the cohesiveness variable $(F=18.31, d f=1 / 88, p<.01)$, indicating that the group high in cohesiveness recalled more tasks than the low group. The main effect for the recall condition was also significant $(F=3.80, d f=2 / 176, p<.05)$. The two independent variables did not enter into any significant interaction $(F=0.95, d f=2 / 176)$. Subsequent $F$ tests (Winer, 1962) to compare the three treatment conditions with one another indicated the number of tasks recalled under "Y-I" condition was greater than under " $\mathrm{N}$ " condition $(F z 7.51, d f=$ $1 / 176, p<.01)$. The comparison of the number of tasks recalled under "Y- $\mathrm{C}$ " and " $\mathrm{N}$ " $(F=$ $1.32, d f=1,476)$ and "Y-C" and "Y-I" $(F=2.58, d f=1 / 176)$ did not show any significant difference. A similar comparison was made for the groups separately. In the case of the high group, more tasks were recalled under "Y-I" than under "N" $(F=7.57, d f=1 / 176, p<.01)$ or "Y-C" condition $(F=4.00, d f=1 / 176, p<.05)$. The difference between " $Y-C$ " and " $N$ " was not significant $(F=0.56, d f=1 / 176)$. None of the comparisons for the groups low in cohesiveness resulted in a significant difference.

The scores on all eight questions in the Post-experimental Questionnaire were summed up for each subject in both the high and low cohesive groups. A $t$ test indicated a significant difference $(p<$ .01 ) in cohesiveness in the expected direction for the two groups. 


\section{DISCUSSION}

The results indicate that the total number of tasks recalled by the highly cohesive group subjects under all three experimental conditions was greater than the number of tasks recalled by low cohesive group subjects. These findings confirm Schachter's (1951) suggestion that a higher level of cohesiveness would increase a subject's acceptance of the group's goal. The increased acceptance according to Horwitz (1954) would be reflected in a stronger tension system, hence, in a greater recall of tasks. It also seems plausible that, because of greater interest in the group tasks, the highly cohesive subjects probably paid closer attention to what they were doing; consequently, this attention led to better recall. Attention has generally been recognized as a variable thac helps the remembering process (Bandura, 1972).

Horwitz (1954) had successfully predicted that "Y-I" tasks would be recalled more than " $Y-C$ " or "N" tasks, because only "Y-I" tasks had a tension system value greater than zero. Our results for the high and low cohesive groups combined show that "Y-I" tasks were recalled better than " $\mathrm{N}$ " tasks but not better than "Y-C" tasks. However, highly cohesive subjects produced data in agreement with Horwitz's findings. The subjects low in cohesiveness, on - the other hand, did not recall any of the three tasks better than any other. Lewin's (1951) tension system theory would explain that instructions given to create the low cohesive groups did not allow for the various tension systems to be activated.

Therefore, the recall of tasks would be equal for the three different treatments in the groups low in cohesiveness.

It is of interest to note that Horwitz's groups of subjects were all composed of sorority girls who knew each other before they participated in the experiment. Moreover, before the beginning of the puzzle-completion tasks, they were involved in a brief group discussion. These groups of subjects could easily be labelled as highly cohesive groups. Consequently, it is not surprising that Horwitz's results agree with the findings concerning the highly cohesive group in this study but not with those of the low cohesive group. It appears that the tension systems are activated in the highly cohesive groups but not in the groups low in cohesiveness.

\section{REFERENCES}

BANDURA, A. Modeling theory: some traditions, trends, and disputes. In R. D. Parke (Ed.), Recent trends in social learning theory. New York: Academic Press, 1972. Pp. 35-61.

BLOMMERS, P., \& LINDQUIST, E. F. Elementary statisrical methods in psychology and education. lowa City: State Univer. of lowa Press, 1960.

HORWITZ, M. The recall of interrupted group tasks: an experimental study of individual motivation to group goals. Human Relations, 1954, 7, 3-38.

KRECH, D., CRUTCHFIELD, R. S., \& BALLACHEY, E. L. Individual in society. New York: McGraw-Hill, 1962. LEWIN, K. Field theory in the social sciences. New York: Harper, 1951.

SCHACHTER, S. Deviation, rejection and communication. Journal of Abnormal and Social Psychology, 1951,. 56, 190-207.

WINER, B. J. Statistical principles in experimental design. New York: McGraw-Hill, 1962.

ZEIGARNIK, B. Das Behalten erledigter Handlungen. Psychol. Forsch., 1927, 9, 1-85 [Summarized in K. Lewin, Field theory in the social sciences. New York: Harper, 1951]. 